\title{
PENANGANAN GENANGAN DENGAN SISTEM POLDER PADA WILAYAH KOTA BANJARMASIN
}

\author{
Solikin $^{1}$, Ery Suhartanto ${ }^{2}$ Riyanto Haribowo ${ }^{2}$ \\ 1) Mahasiswa Magister Sumber Daya Air, Fakultas Teknik, Universitas Brawijaya \\ 2) Dosen Magister Sumber Daya Air, Fakultas Teknik, Universitas Brawijaya \\ E-mail : ikien@ymail.com ${ }^{1)}$, erysuhartanto@ub.ac.id ${ }^{2)}$,riyanto_haribowo@ub.ac.id ${ }^{2)}$
}

\begin{abstract}
ABSTRAK: Hujan seringkali mengakibatkan genangan di wilayah Banjarmasin. Hujan 30 Maret 2016, mengakibatkan genangan (tinggi $\pm 8-60 \mathrm{~cm}$ ) di Satuan Wilayah Penanganan Genangan (SWPG) Sudi Mampir. Tujuan penelitian ini mengkaji kapasitas drainase eksisting dan pengaruh pasang Sungai Martapura. Hujan rancangan dihitung dengan Log Pearson III. Debit banjir saluran drainase dihitung dengan Metode Rasional. Perhitungan debit banjir Sungai Martapura digunakan Metode HSS Nakayasu. Pemodelan profil aliran sungai dengan HEC-RAS v5.01. Perhitungan backwater pada S. Telawang dengan Metode Tahapan Langsung. Hasil analisis, hujan yang terjadi

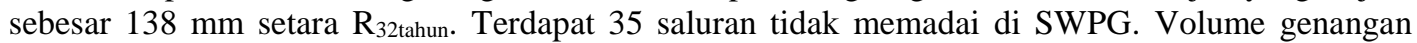
akibat hujan di SWPG sebesar 54.470,07 $\mathrm{m}^{3}$, dengan tinggi rerata di lahan $10.3 \mathrm{~cm}$ dan $47 \mathrm{~cm}$ di jalan. Debit Sungai Martapura saat kejadian setara $\mathrm{Q}_{2 \text { tahun }}\left(566.54 \mathrm{~m}^{3} / \mathrm{dtk}\right)$. Volume dan luas genangan akibat luapan sungai di SWPG 2.216,68 $\mathrm{m}^{3}$ dan 11.093,26 $\mathrm{m}^{2}$. Tinggi rerata genangan di kawasan sekitar sungai $\pm 20 \mathrm{~cm}$. Upaya penanganan yang perlu dilakukan sesuai hasil analisa untuk menghindari genangan adalah dengan melakukan normalisasi saluran drainase, pembuatan tanggul dan pembuatan sistem polder.
\end{abstract}

Kata kunci: Drainase, Genangan, Back Water, Pasang Surut, Polder

\begin{abstract}
The rainfall often cause inundation in the area of Banjarmasin. Rainfall on March 30, 2016, cause inundation (high $\pm 8-60 \mathrm{~cm}$ ) in SWPG Sudi Mampir. The purpose of this study to examine the capacity of the existing drainage and tidal influence of Martapura River. Maximum Rainfall with certain return period calculated by Log Pearson III. Maximum Discharge in drainage channels are calculated with Rational Method. Martapura River flood discharge calculation used Nakayasu HSS Method. Modeling of river flow profile with HEC-RAS v5.01. Calculation of back water in Telawang River used Direct Step Method. The results of the analysis, the rainfall that occurred at $138 \mathrm{~mm}$ equivalent $R_{32 t a h u n}$. There are 35 channels in SWPG inadequate. Volume of inundation rainfall in $S W P G$ is $54470.07 \mathrm{~m}^{3}$, with a mean height in the land $10.3 \mathrm{~cm}$ and $47 \mathrm{~cm}$ on the roads. Discharge of Martapura river at the time equivalent $Q_{2 t a h u n}\left(566.54 \mathrm{~m}^{3} / \mathrm{sec}\right)$. Volume and area of inundation due overflow of Martapura Rivers in SWPG is $2216.68 \mathrm{~m}^{3}$ and $11093.26 \mathrm{~m}^{2}$. High average inundation in the area around the Martapura River is $\pm 20 \mathrm{~cm}$. The effort required according to analysis result to avoid inundation problems is normalization of drainage channel, levee construction and Polder system.
\end{abstract}

Keywords: Drainage, Inundation, Back Water, Tidal, Polder

Kota Banjarmasin adalah Ibu Kota Provinsi Kalimantan Selatan, merupakan Kota Pusat Pemerintahan, Kota Pusat Kegiatan wilayah, Kota Gerbang Nasional dan termasuk sebagai salah satu Kota Pusat Kegiatan Ekonomi Nasional. Kota Banjarmasin terletak di tepian Sungai Barito dan Sungai Martapura, sebagian besar wilayahnya berupa lahan rawa (Kimpraswil, 2002).
Ketinggian muka air sungai-sungai di wilayah Kota Banjarmasin umumnya mengacu pada pasang surut air Sungai Barito dan Sungai Martapura. Semua pasokan air sungai yang ada, utamanya dipengaruhi oleh pasokan air dari muara Sungai Barito sebagai sungai utama (Muhlis dkk, 2012).

Seiring dengan perkembangan kota, luas lahan, sungai, dan kanal sebagai kawasan 
tampungan air jumlahnya makin berkurang (Kimpraswil, 2002). Saat muka air sungai naik karena pasang, terjadi aliran balik ke dalam sungai, saluran drainase dan daerah rawa. Sehingga permukaan air lebih tinggi dari sebagian besar lahan dan menyebabkan terjadinya genangan pada daerah dengan topografi rendah. Genangan makin luas dan tinggi bila terjadi hujan yang waktunya bersamaan dengan pasang air sungai tinggi (DSDAD Kota Banjarmasin, 2013).

Genangan di beberapa wilayah Kota Banjarmasin umumnya diakibatkan oleh dua hal, yaitu hujan dan luapan sungai. Genangan karena kejadian hujan. Ada dua kemungkinan penyebab terjadinya genangan karena hujan di suatu kawasan. Pertama, intensitas hujan lebih besar daripada perhitungan dalam perencanaan saluran drainase. Kedua, intensitas hujan sesuai dengan perencanaan akan tetapi limpasan air hujan tidak mampu ditampung oleh saluran drainase yang ada (Munadhir, 1995 dalam Susilowati, 2006).

Genangan yang diakibatkan oleh luapan pasang air Sungai Martapura. Sungai Martapura merupakan bagian dari Daerah Aliran Sungai (DAS) Sungai Barito yang memegang peranan penting terhadap terjadinya genangan di Kota Banjarmasin, sebab letak Kota Banjarmasin di bagian hilir dari DAS Martapura (Muhlis dkk. 2012).

Penanganan genangan drainase di wilayah Kota Banjarmasin sesuai hasil studi terdahulu terbagi dalam 26 Satuan Wilayah Penanganan Genangan (SWPG) (Bappeda Prov Kalsel, 1999). Salah satu diantaranya adalah SWPG Sudi Mampir yang digunakan sebagai lokasi studi penelitian.

Hasil survei genangan berdasarkan studi terdahulu di wilayah SWPG Sudi Mampir, utamanya di beberapa ruas jalan protokol berkisar 10-20 cm (DSDAD Kota Banjarmasin, 2013), berkisar 15-20 cm (Jawapos.com) dan hasil survei lapangan $8-60 \mathrm{~cm}$ di beberapa kawasan.

Penelitian ini dilakukan untuk mengkaji kapasitas tampungan saluran drainase eksisting, mengetahui bagaimana pengaruh pasang Sungai Martapura terhadap sebaran genangan dan menghasilkan penanganan terhadap hasil analisis genangan yang terjadi.

\section{DATA DAN METODE}

Metode untuk memperkirakan laju aliran permukaan puncak yang umum dipakai adalah metode Rasional. Metode ini sangat simpel dan mudah penggunaannya, namun penggunaannya untuk daerah dengan ukuran kecil (Suripin, 2004).

$$
\mathrm{Q}=0,278 \text {.C.I.A }
$$

Dimana, $\mathrm{Q}$ adalah debit tertinggi untuk periode ulang $\mathrm{t}$ tahun (dalam $\mathrm{m}^{3} / \mathrm{det}$ ), $\mathrm{A}$ adalah luas daerah aliran hujan (dalam $\mathrm{km}^{2}$ ), I adalah intensitas hujan (dalam $\mathrm{mm} / \mathrm{jam}$ ), dan $\mathrm{C}$ adalah koefisien aliran.

Evaluasi kapasitas saluran dimaksudkan untuk meninjau kemampuan saluran drainase eksisting dengan debit banjir rancangan yang terjadi. Pada dasarnya debit yang mampu dilewatkan oleh suatu saluran drainase dapat dilakukan dengan pendekatan menggunakan rumus Manning (Suhardjono, 2015).

$$
\begin{aligned}
& Q_{\text {sal }}=V_{\text {sal }} \times A_{\text {sal }} \\
& V=\frac{1}{n} \times R^{2 / 3} \times I^{1 / 2}
\end{aligned}
$$

Dimana, $\mathrm{Q}_{\text {sal }}$ adalah debit (dalam $\mathrm{m}^{3} / \mathrm{dtk}$ ), $\mathrm{V}_{\text {sal }}$ adalah kecepatan aliran di saluran (dalam $\mathrm{m} / \mathrm{dtk}), A_{\text {sal }}$ adalah luas penampang basah (dalam $\mathrm{m}^{2}$ ), $\mathrm{Q}$ adalah debit (dalam $\mathrm{m}^{3} / \mathrm{det}$ ), A adalah luas penampang basah $\left(\right.$ dalam $\mathrm{m}^{2}$ ), $\mathrm{R}$ adalah jari-jari hidraulis (dalam $\mathrm{m}$ ), I adalah kemiringan dasar saluran, dan adalah koefisien kekasaran Manning.

Peninjauan genangan yang terjadi karena pasang air sungai dilakukan dengan melakukan simulasi pemodelan menggunakan program HEC-RAS.

HEC-RAS merupakan program aplikasi untuk memodelkan aliran air di sungai, River Analysis System (RAS), yang dibuat dan dikembangkan oleh Hydrologic Engineering Center (HEC), yang merupakan bagian dari Institute for Water Resources (IWR), dibawah U.S. Army Corps of Engineers (USACE).

Program ini adalah program yang di desain untuk menjalankan perhitungan hidraulik satu dimensi dan dua dimensi untuk jaringan sungai/saluran alami maupun saluran buatan (Hendrasari, 2015). Salah satu keistimewaan dalam HEC-RAS versi 5.01 berupa tambahan feature untuk analisis dua dimensi. Sehingga dapat digunakan untuk memodelkan sebaran genangan akibat luapan Sungai Martapura.

HEC-RAS versi 5.01 memiliki empat komponen analisa sistem sungai satu dimensi dan satu komponen analisa sistem sungai dua dimensi yang terdiri dari: 
1. Simulasi perhitungan aliran tetap (Steady Flow)

2. Simulasi perhitungan aliran tidak tetap (Unsteady Flow)

3. Simulasi transport sedimen (Sediment Transport)

4. Simulasi kualitas air (Water Quality)

5. Floodplain Mapping

Sistem Polder adalah suatu penanganan drainase perkotaan dengan cara mengisolasi daerah yang dilayani (catchmen area) terhadap masuknya air dari luar sistem baik berupa overflow (limpasan) maupun aliran bawah permukaan serta mengendalikan ketinggian permukaan muka air banjir didalam sistem sesuai dengan rencana (Al Falah, 2000 dalam Nugroho, 2012)

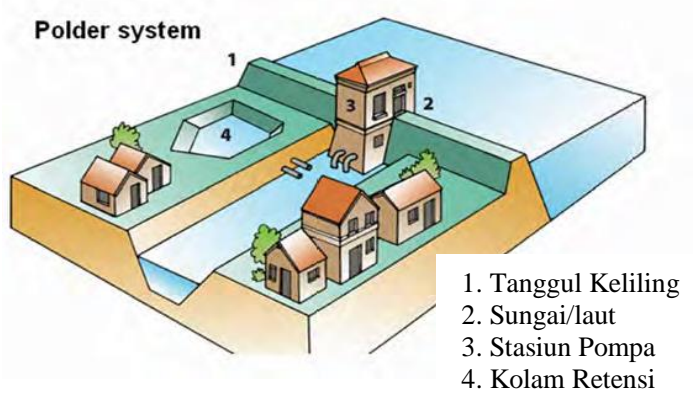

Gambar 1. Elemen Sistem polder

Sumber: Herman Mondeel \& Hermono S Budinetro, dalam Nugroho, 2012

Sistem Polder merupakan penanganan banjir secara terintregasi dengan beberapa elemen yang penting, diantaranya tanggul keliling yang melindungi dari pasang air laut, stasiun pompa yang berguna untuk mengontrol elevasi air dan kolam retensi untuk menampung sementara air yang kemudian dialirkan ke badan penerima air (Herman Mondeel \& Hermono S Budinetro, dalam Nugroho, 2012).

Analisa penelusuran banjir lewat kolam tampungan dilakukan dengan rumus (Limantara, 2010):

$\left(\frac{l_{1}+l_{2}}{2}\right) * \Delta t+\left(s_{1}-\frac{o_{1}}{2} \Delta t\right)=\left(s_{2}+\frac{o_{2}}{2} \cdot \Delta \Delta\right)$

Dimana, $\mathrm{I}_{1}$ adalah inflow pada saat $\mathrm{t} 1, \mathrm{I}_{2}$ adalah inflow pada saat $\mathrm{t} 2, \Delta \mathrm{t}$ adalah interval waktu antara $\mathrm{t} 1$ dan $\mathrm{t} 2, \mathrm{O}_{1}$ adalah outflow pada saat $\mathrm{t} 1$, $\mathrm{O}_{2}$ adalah outflow pada saat $\mathrm{t} 2, \mathrm{~S}_{1}$ adalah Storage pada saat $t 1$ dan $S_{2}$ adalah Storage pada saat $\mathrm{t} 2$.
Perhitungan penelusuran banjir pada Polder menggunakan prinsip penelusuran banjir pada kolam tampungan untuk meninjau kemampuan Polder yang direncanakan. Kapasitas pompa yang digunakan sesuai dengan kemampuan polder.

\section{Pengumpulan Data}

Data-data yang digunakan dalam penelitian adalah berupa data primer dan data sekunder. Data primer diperoleh dengan melakukan observasi pengamatan dan pengukuran langsung di lapangan. Data primer yang digunakan terdiri dari data saluran drainase eksisiting (dimensi, outlet, arah aliran, kondisi sedimen eksiting) dan data pasang surut pada bagian hilir Sungai Martapura.

Untuk mendapatkan data pasut pada bagian hilir Sungai Martapura dilakukan observasi pengamatan dan pengukuran selama 16 hari. Observasi dilakukan pada tanggal 19 Juli sampai dengan 5 Agustus 2016 di titik

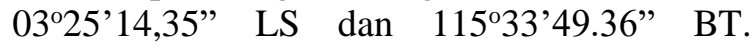
(mengingat kesukaran dan keamanan penempatan peralatan pasut).

Agar hasil pengamatan pasut pada bagian hilir terintegrasi dengan hasil pangamatan pada stasiun AWLR Menara Pandang yang terletak di $03^{\circ} 19^{\prime} 01,8^{\prime \prime}$ LS dan $114^{\circ} 35^{\prime} 34.7^{\prime \prime}$ BT. maka dilakukan pengikatan elevasi pada lokasi pengamatan di bagian hilir (pengikatan dan penarikan elevasi berdasarkan nilai BM terdekat, yaitu BM 02 yang terletak di Jembatan Faisal - Teluk Dalam). Data primer selanjutnya berupa data pasang historis Sungai Martapura (wawancara dan observasi).

Data sekunder merupakan data yang didapatkan atau bersumber dari instansi-instansi terkait dan pernah melakukan pengukuran. Data sekunder yang digunakan pada penelitian ini terdiri dari, data curah hujan dari Stasiun Surgi Mufti selama 15 tahun, Peta topografi hasil pemetaan dari Lidar tahun 2012, Peta tata guna lahan tahun 2012, data dimensi saluran drainase dari instansi terkait, data tinggi muka air pada Sungai Martapura pada Stasiun AWLR Menara Pandang, Data batimetri Sungai Martapura 2015.

\section{Pengolahan Data}

Untuk melakukan evaluasi kapasitas saluran drainase eksisting pada tanggal 30 Maret 2016, dilakukan tahapan analisis perhitungan yang terdiri beberapa tahap: 
1. Melakukan uji konsistensi data curah hujan

2. Menghitung curah hujan rancangan dengan Metode Log Pearson Type III

3. Analisa uji kesesuaian distribusi dengan uji Chi Kuadrat dan uji Smirnov Kolmogorov

4. Melakukan perhitungan intensitas hujan dengan menggunakan rumus mononobe

5. Menentukan dan menghitung luas daerah pengaliran (Dpsal) untuk tiap saluran

6. Menghitung debit puncak air hujan dengan Metode Rasional dari tiap ruas saluran

7. Menghitung kapasitas tampungan saluran drainase eksisting sesuai dengan bentuk/dimensi dari saluran eksisting di lapangan

8. Analisa perbandingan/evaluasi kapasitas saluran eksisting terhadap debit banjir

Untuk melakukan evaluasi terhadap kondisi Sungai Marapura pada tanggal 30 Maret 2016, tahapan analisis yang perlu dilakukan adalah sebagai berikut:

1. Menghitung dan menentukan tinggi elevasi pasang sesuai dengan data observasi dan data pasang historis sebagai input boundary condition hilir Sungai Martapura.

2. Melakukan analisa Regresi Linear, untuk melihat hubungan muka air Sungai Martapura di bagian hilir dan tengah sesuai dengan hasil data pengamatan dan hasil data Stasiun AWLR Menara Pandang. Dari persamaan hasil analisa regresi linear dapat diketahui profil muka air Sungai Martapura pada kejadian 30 Maret 2016. Hasil tinggi muka air dari persamaan analisa regresi linear akan digunakan sebagai kalibrasi pada profil muka air hasil simulasi model dari program HECRASv5.01.

3. Menghitung curah hujan rancangan dengan Metode Log Person Type III

4. Analisa uji kesesuaian distribusi, yaitu uji Chi Kuadrat dan uji Smirnov Kolmogorov

5. Menghitung debit banjir rancangan Sungai Martapura dengan Metode HSS Nakayasu.

6. Input data dalam program HEC-RAS berupa data pasang, debit banjir rancangan, geometri sungai, dan DEM

7. Running program HEC-RAS untuk analisa pemodelan profil muka air sungai dan genangan pada tanggal 30 Maret 2016

8. Berikutnya memilih salah satu SWPG Sudi Mampir untuk melakukan analisa perhitungan/perencanaan penanganan genangan berdasarkan kondisi lokasi dan lahan yang tersedia.

\section{HASIL DAN PEMBAHASAN}

\section{Lokasi Studi}

Keterbatasan data yang tersedia, sehingga studi lebih berfokus pada area SWPG Sudi Mampir dan luapan Sungai Martapura pada wilayah administrasi Kota Banjarmasin. Secara geografis SWPG Sudi Mampir terletak di dalam wilayah Kota Banjarmasin, di antara $3^{\circ} 16^{\prime} 46^{\prime \prime}$ sampai dengan 3'22'54" Lintang Selatan dan $114^{\circ} 31^{\prime} 40^{\prime \prime}$ sampai dengan 11439'55" Bujur Timur.

SPWG Sudi Mampir sesuai hasil analisis memiliki luas mencapai $\pm 0.53 \mathrm{~km}^{2}$ dari luas Kota Banjarmasin yang mencapai $\pm 98.46 \mathrm{~km}^{2}$.

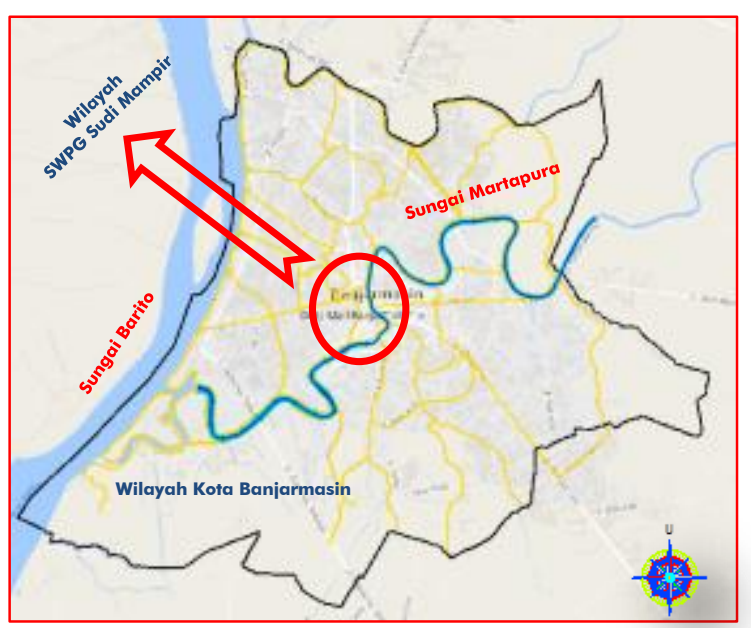

Gambar 2. Lokasi Penelitian

Sumber: Google Map, 2016

Gambar 2 menunjukkan lokasi SPWG Sudi Mampir dalam wilayah administrasi Kota Banjarmasin (dalam lingkaran warna merah). Garis hitam merupakan wilayah administrasi Kota Banjarmasin. Terdapat dua buah sungai utama, yaitu Sungai Barito dan Sungai Martapura. Sungai Martapura merupakan sungai yang melintas tengah kota dan membelah Kota Banjarmasin.

Untuk wilayah kawasan SPWG Sudi Mampir ditunjukkan pada Gambar 3. Variasi warna dalam Gambar 3 menunjukkan luas Daerah Pengaliran Saluran (DPSal) dari masing-masing tangkapan per saluran drainase. 


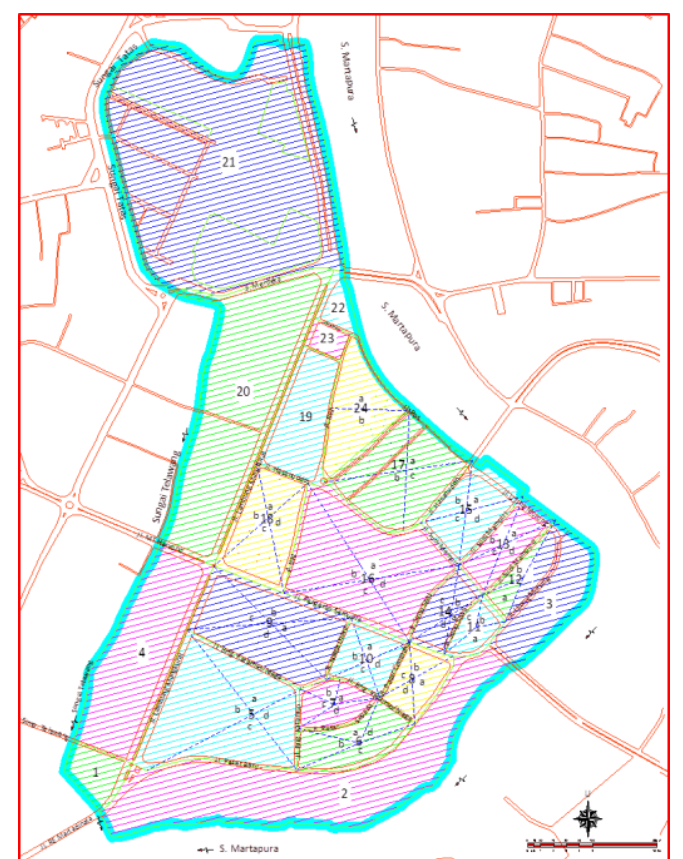

Gambar 3. Lokasi Penelitian SWPG Sudi Mampir

Sumber: Google Map, 2016

\section{Evaluasi Terhadap Kapasitas Saluran Drainase Eksisting}

Pada saat kejadian hujan yang tercatat pada ARR Menara Pandang sebesar $48 \mathrm{~mm} / \mathrm{jam}$, dengan melakukan hitungan terbalik didapatkan nilai curah hujan (R) sebesar 138,46 $\mathrm{mm}$ setara dengan hujan rancangan dengan kala ulang 32 tahun, dengan nilai Cs sebesar 1.2957 dan nilai $G$ sebesar 2.2621. Dimana hasil analisa frekuensi terhadap data curah hujan Stasiun Surgi Mufti didapatkan nilai curah hujan rancangan dengan berbagai kala ulang disajikan pada Tabel 1 .

Tabel 1. Curah Hujan Rancangan Stasiun Surgi Mufti

\begin{tabular}{|c|c|c|}
\hline No & Kala Ulang & $\begin{array}{c}\text { Curah } \\
\text { Hujan }\end{array}$ \\
\hline 1 & 1.01 & 47.30 \\
\hline 2 & 2 & 66.89 \\
\hline 3 & 5 & 87.91 \\
\hline 4 & 10 & 105.50 \\
\hline 5 & 20 & 127.37 \\
\hline 6 & 25 & 132.27 \\
\hline 7 & 50 & 155.86 \\
\hline
\end{tabular}

Sumber: hasil perhitungan

Evaluasi kapasitas saluran drainase eksisting terhadap debit banjir (limpasan) kejadian 30 Maret 2016 ditunjukkan pada gambar 4 dan gambar 5 .

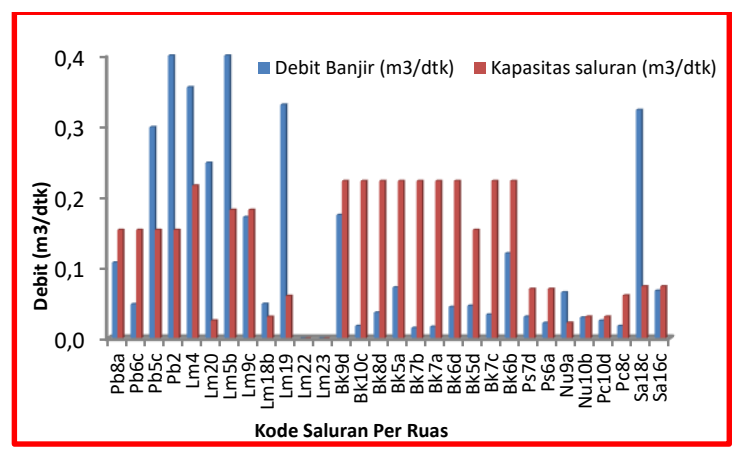

Gambar 4. Perbandingan debit banjir 32 tahunan dengan kapasitas saluran Sumber: hasil analisis

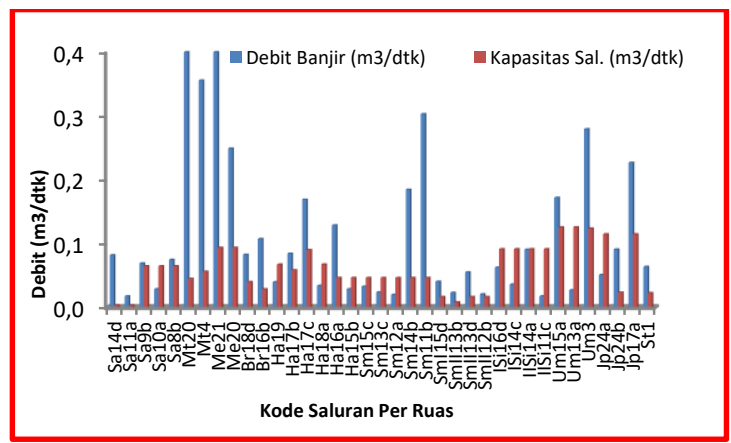

Gambar 5. Perbandingan debit banjir 32 tahunan dengan kapasitas saluran (lanjutan) Sumber: hasil analisis

Berdasarkan pada Gambar 4 dan Gambar 5 dapat disimpulkan bahwa kapasitas saluran drainase eksisting di SWPG Sudi Mampir dari total keseluruhan, lebih dari setengah jumlah total tidak mampu menampung debit banjir yang terjadi 30 Maret 2016. Ada 35 ruas saluran yang tidak mampu untuk menampung debit kejadian sehingga air melimpas dan menggenang.

\section{Kondisi Genangan Akibat Hujan}

Jumlah genangan hujan yang melimpas pada tanggal 30 Maret 2016 sebesar 54.470,07 $\mathrm{m}^{3}$. Hasil perhitungan lengkap disajikan pada Tabel 2.

Dengan menggunakan bantuan software autocad dapat diketahui luas lahan dan luas jalan yang ada di SWPG Sudi Mampir.

Luas Lahan $\quad=0.530 \mathrm{~km}^{2}=530.290,10 \mathrm{~m}^{2}$

Luas Jalan $\quad=0.116 \mathrm{~km}^{2}=115.617,85 \mathrm{~m}^{2}$

Tinggi rata-rata genangan air hujan di lahan pada SWPG Sudi Mampir $\quad=0.10272 \mathrm{~m}$ $=10.272 \mathrm{~cm}$

Tinggi rata-rata genangan air hujan di jalan pada SWPG Sudi Mampir $\quad=0.471 \mathrm{~m}$ $=47.112 \mathrm{~cm}$ 
Tabel 2. Volume Genangan Akibat Hujan

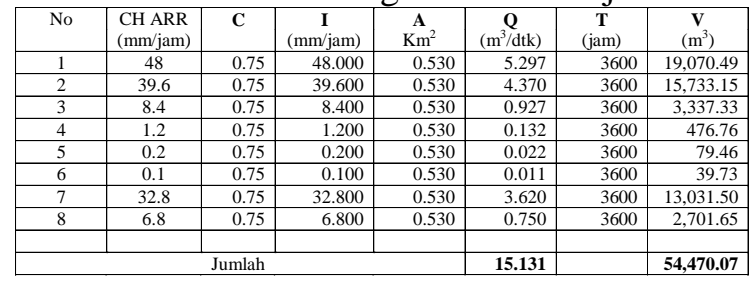

Sumber: hasil perhitungan

\section{Evaluasi Terhadap Kondisi Sungai Martapura}

\section{Pasang Surut}

Sesuai hasil data pengamatan pasang surut di bagian hilir Sungai Martapura dilakukan analisa untuk menentukan jenis pasut dengan melakukan perhitungan bilangan Farrmzahl, sehingga didapatkan hasil perhitungan sebagai berikut:

$$
\begin{aligned}
\mathrm{F} & =(0.3096+0.2329) /(0.2611+0.0739) \\
& =1.62
\end{aligned}
$$

Hasil perhitungan terhadap konstanta harmoni didapatkan data-data elevasi penting yang disajikan pada Tabel 3 .

Tabel 3. Elevasi-Elevasi Penting Pasang Surut

\begin{tabular}{|l|c|c|}
\hline Keterangan & $\begin{array}{c}\text { Pengamatan } \\
\text { Elev. }(\mathrm{m})\end{array}$ & $\begin{array}{c}\text { Peramalan } \\
\text { Elev. }(\mathrm{m})\end{array}$ \\
\hline Higher High Water Level & 2.62 & 3.00 \\
\hline Mean High Water Level & 2.54 & 2.60 \\
\hline Mean Sea Level & 1.78 & 1.80 \\
\hline Mean Low Water Level & 0.74 & 1.00 \\
\hline Lower Low Water Level & 0.64 & 0.50 \\
\hline
\end{tabular}

Sumber: hasil analisa

Dapat disimpulkan jenis pasang surut pada lokasi studi termasuk pasang surut campuran yang condong ke tunggal (mixed dominant diurnal).

\section{Hubungan Tinggi Muka Air Sungai Martapura}

Dengan menggunakan data hasil pengamatan dan data AWLR Stasiun Menara Pandang didapatkan hubungan tinggi muka air hilir dan muka air pada Stasiun AWLR Menara Pandang yang disajikan pada Gambar 6 . Sehingga didapatkan persamaan $\mathrm{y}=1.5917 \mathrm{x}-$ 1.4743 .

Dengan menggunakan persamaan $\mathrm{y}=1.5917 \mathrm{X}-1.4743$, dapat diestimasi tinggi muka air Sungai Martapura pada bagian hilir, yang akan digunakan sebagai input untuk boundary condition pada program HEC-RAS.

Kejadian $=08$ Februari dan 30 Maret 2016

$$
\begin{array}{ll}
\mathrm{Y} & =1.5917 \mathrm{X}-1.4743 \\
\mathrm{X} & =+2.10 \mathrm{~m} \\
\text { Maka nilai Y } & =1.5917(2.10)-1.4743 \\
& =+1.87 \mathrm{~m}
\end{array}
$$

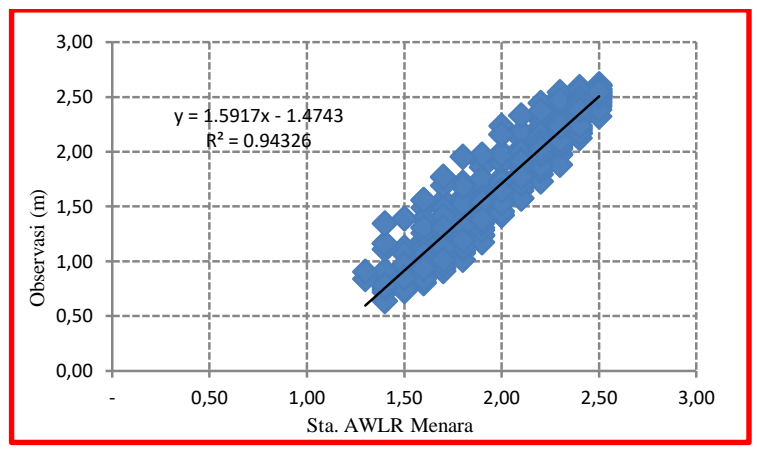

Gambar 6. Grafik Hubungan Tinggi Muka Sungai Martapura

Sumber: hasil analisis

\section{Debit Banjir Rancangan Sungai Martapura}

Perhitungan hidrograf ini digunakan untuk mendukung pemodelan hidrolika dengan menggunakan program HEC-RAS. Hasil perhitungan debit puncak banjir dengan Metode Nakayasu disajikan pada Tabel 4.

Tabel 4. Rekapitulasi Debit Banjir Rancangan

\begin{tabular}{|c|c|}
\hline Kala Ulang & $\begin{array}{c}\text { Debit } \\
\left(\mathrm{m}^{3} / \mathrm{dtk}\right.\end{array}$ \\
\hline 1.01 & 395.692 \\
\hline 2 & 566.538 \\
\hline 3 & 607.549 \\
\hline 5 & 647.260 \\
\hline 10 & 713.177 \\
\hline 25 & 797.800 \\
\hline 50 & 862.018 \\
\hline 100 & 919.233 \\
\hline
\end{tabular}

Sumber: hasil perhitungan

Berdasarkan hasil simulasi dari beberapa debit diketahui profil muka air Sungai Martapura kondisi eksisting yang paling mendekati dengan kondisi realita pada saat kejadian tanggal 30 Maret 2016 adalah hasil simulasi debit dengan kala ulang 2 tahun $\left(\mathrm{Q}_{2 \text { thn }}\right.$ $=566.54 \mathrm{~m}^{3} / \mathrm{dtk}$ ).

Profil muka air hasil simulasi HEC-RAS untuk $\mathrm{Q}_{2 \text { tahun }}$ mendekati profil muka air pada saat kejadian 30 Maret 2016. Tinggi muka air hasil simulasi patok 29 (Stasiun Menara Pandang) pada elevasi $+2.23 \mathrm{~m}$. Dimana saat 
kejadian 30 Maret tinggi muka air pada patok 29 pada elevasi $+2.90 \mathrm{~m}$.

Hasil simulasi cross section patok 29 disajikan pada Gambar 7. Analisa perhitungan hasil Running HEC-RAS untuk debit banjir rancangan $\mathrm{Q}_{\text {2tahun }}$ pada kapasitas tampungan Sungai Martapura disajikan dalam Tabel 5.

Tabel 5. Rekapitulasi Hasil Running HEC-RAS

\begin{tabular}{|c|c|c|c|c|}
\hline \multirow{2}{*}{ Patok } & \multirow{2}{*}{$\begin{array}{c}\text { Elevasi } \\
\text { Dasar } \\
\text { Saluran }\end{array}$} & \multirow{2}{*}{$\begin{array}{c}\text { Elevasi } \\
\text { Tanggul }\end{array}$} & \multicolumn{2}{|c|}{ Q 2 thn (08 Feb dan 30 Maret) } \\
\hline & & & Elevasi Muka air & Kondisi \\
\hline & $(\mathrm{m})$ & $(\mathrm{m})$ & $(\mathrm{m})$ & \\
\hline 49 & -7.50 & 2.00 & 2.68 & Melimpas \\
\hline 48 & -7.50 & 2.00 & 2.67 & Melimpas \\
\hline 47 & -9.50 & 2.00 & 2.66 & Melimpas \\
\hline 46 & -8.00 & 2.00 & 2.63 & Melimpas \\
\hline 45 & -8.80 & 2.00 & 2.61 & Melimpas \\
\hline 44 & -9.50 & 2.00 & 2.60 & Melimpas \\
\hline 43 & -9.00 & 2.00 & 2.58 & Melimpas \\
\hline 42 & -9.00 & 2.00 & 2.57 & Melimpas \\
\hline 41 & -8.00 & 2.00 & 2.55 & Melimpas \\
\hline 40 & -11.00 & 2.00 & 2.54 & Melimpas \\
\hline 39 & -8.00 & 2.00 & 2.53 & Melimpas \\
\hline 38 & -8.00 & 2.00 & 2.51 & Melimpas \\
\hline 37 & -8.00 & 2.00 & 2.50 & Melimpas \\
\hline 36 & -8.00 & 2.00 & 2.47 & Melimpas \\
\hline 35 & -8.00 & 2.00 & 2.46 & Melimpas \\
\hline 34 & -10.00 & 2.00 & 2.42 & Melimpas \\
\hline 33 & -7.00 & 2.00 & 2.40 & Melimpas \\
\hline 32 & -8.00 & 2.00 & 2.33 & Melimpas \\
\hline 31 & -11.00 & 2.00 & 2.29 & Melimpas \\
\hline 30 & -10.00 & 2.00 & 2.28 & Melimpas \\
\hline 29 & -11.00 & 2.00 & 2.23 & Melimpas \\
\hline 28 & -12.00 & 2.00 & 2.20 & Melimpas \\
\hline 27 & -11.00 & 2.00 & 2.18 & Melimpas \\
\hline 26 & -11.50 & 2.00 & 2.08 & Melimpas \\
\hline 25 & -11.00 & 2.00 & 2.09 & Melimpas \\
\hline 24 & -10.00 & 2.00 & 2.09 & Melimpas \\
\hline 23 & -12.00 & 2.00 & 2.07 & Melimpas \\
\hline 22 & -8.00 & 2.00 & 2.03 & Melimpas \\
\hline 21 & -13.00 & 2.00 & 2.04 & Melimpas \\
\hline 20 & -11.00 & 2.00 & 2.01 & Melimpas \\
\hline 19 & -6.50 & 2.00 & 1.99 & Aman \\
\hline 18 & -8.50 & 2.00 & 1.97 & Aman \\
\hline 17 & -6.50 & 2.00 & 1.96 & Aman \\
\hline 16 & -6.50 & 2.00 & 1.94 & Aman \\
\hline 15 & -10.00 & 2.00 & 1.92 & Aman \\
\hline 14 & -7.00 & 2.00 & 1.90 & Aman \\
\hline 13 & -7.50 & 2.00 & 1.88 & Aman \\
\hline 12 & -11.00 & 2.00 & 1.87 & Aman \\
\hline 11 & -10.50 & 2.00 & 1.87 & Aman \\
\hline
\end{tabular}

Sumber: hasil perhitungan

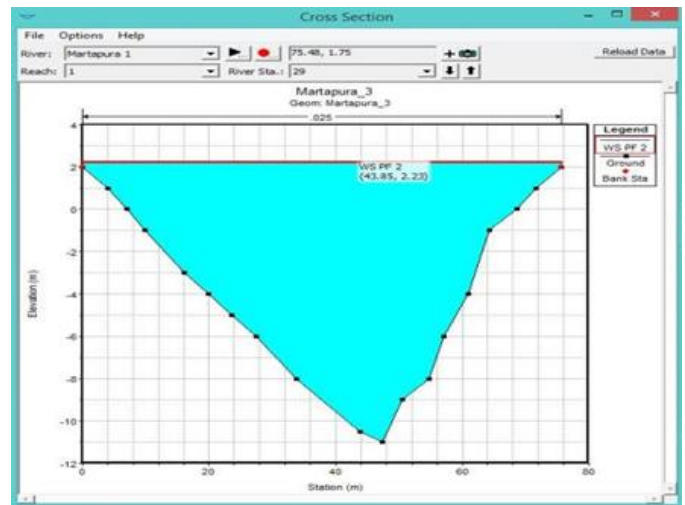

Gambar 7. Cross Section Sungai Martapura Patok 29 (30 Maret 2016)

Sumber: hasil analisis

\section{Kondisi Genangan Akibat Luapan Sungai Martapura}

Dari proses yang sudah dilakukan maka dapat dilihat hasil analisa genangan yang terjadi. Berikut pada Gambar 8 disajikan hasil dari sebaran genangan air akibat luapan air sungai dengan debit $\mathrm{Q}_{2 \text { tahun }}$ untuk kejadian 30 Maret 2016.

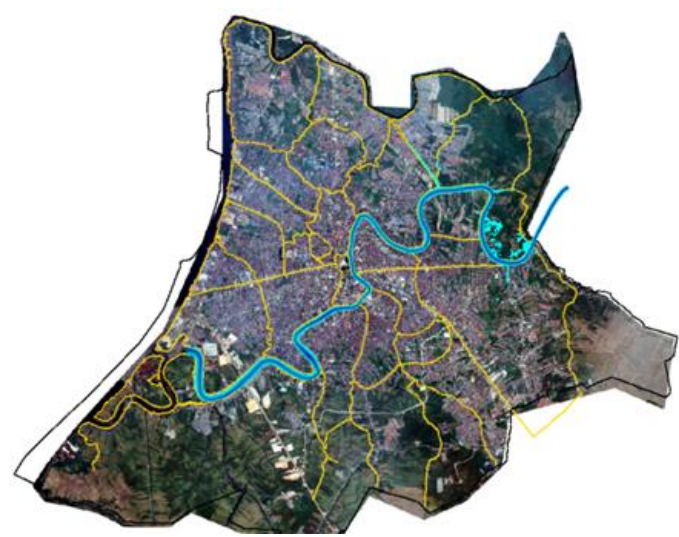

Gambar 8. Sebaran Genangan Akibat Luapan Sungai $\mathrm{Q}_{2 \text { tahun }}$ (30 Mar 2016)

Sumber: hasil analisis

Hasil simulasi program HEC-RAS v5.01 dengan $\mathrm{Q}_{2 \text { tahun }}$ dapatkan disimpulkan bahwa hampir seluruh ruas penampang Sungai Martapura (dari hilir hingga hulu) melimpas, elevasi muka air pada patok 11 (hilir) $+1.87 \mathrm{~m}$ dan pada patok 49 (hulu) $+2.68 \mathrm{~m}$.

Kenaikan muka air Sungai Martapura pada tanggal 30 Maret 2016 mengakibatkan terjadinya pembendungan aliran dari saluransaluran drainase sehingga air hujan yang turun pada saat kejadian melimpah dan menggenang. Luas genangan akibat luapan Sungai Martapura sesuai hasil simulasi program HEC-RAS disajikan pada Tabel 6 .

Tabel 6. Luas Genangan akibat luapan Sungai Martapura

\begin{tabular}{|l|c|}
\hline \multicolumn{1}{|c|}{ Debit } & $\begin{array}{c}\text { luas } \\
\text { Genangan } \\
\text { Lahan }\end{array}$ \\
\hline & $\mathrm{m}^{2}$ \\
\hline Q 2 thn (30 Maret 2016) & $372,944.46$ \\
\hline Q 5 thn & $4,192,953.47$ \\
\hline Q 10 thn & $4,742,134.80$ \\
\hline Q 25 thn & $5,340,766.24$ \\
\hline Q 50 thn & $5,898,459.63$ \\
\hline Q 100 thn & $6,278,493.58$ \\
\hline
\end{tabular}

Sumber: hasil perhitungan

Tinggi rata-rata genangan akibat luapan Sungai Martapura di sekitar kawasan sungai sesuai hasil program HEC-RAS disajikan pada Tabel 7. 
Tabel 7. Tinggi Rata-Rata Genangan Akibat Luapan Sungai Martapura

\begin{tabular}{|l|r|}
\hline \multicolumn{1}{|c|}{ Debit } & $\begin{array}{c}\text { Tinggi } \\
\text { Rerata } \\
\text { Genangan di } \\
\text { lahan }\end{array}$ \\
\hline & $\mathrm{m}$ \\
\hline Q 2 thn (30 Maret 2016) & 0.17 \\
\hline Q 5 thn & 0.30 \\
\hline Q 10 thn & 0.35 \\
\hline Q 25 thn & 0.24 \\
\hline Q 50 thn & 0.24 \\
\hline Q 100 thn & 0.26 \\
\hline
\end{tabular}

Volume genangan rata-rata akibat luapan Sungai Martapura di sekitar kawasan sungai sesuai hasil program HEC-RAS disajikan pada Tabel 8.

Tabel 8. Volume Rata-Rata Genangan Akibat Luapan Sungai Martapura

\begin{tabular}{|l|c|}
\hline \multicolumn{1}{|c|}{ Debit } & $\begin{array}{c}\text { Volume } \\
\text { Genangan }\end{array}$ \\
\hline & $\mathrm{m}^{3}$ \\
\hline Q 2 thn (30 Maret 2016) & $61,806.30$ \\
\hline Q 5 thn & $1,257,886.04$ \\
\hline Q 10 thn & $1,659,747.18$ \\
\hline Q 25 thn & $1,262,577.52$ \\
\hline Q 50 thn & $1,410,770.74$ \\
\hline Q 100 thn & $1,657,224.19$ \\
\hline
\end{tabular}

Sumber: hasil perhitungan

Sedangkan hasil perhitungan luas genangan khusus di kawasan SWPG Sudi Mampir disajikan pada Tabel 9.

Tabel 9. Luas Genangan dalam Kawasan SWPG Sudi Mampir

\begin{tabular}{|l|c|}
\hline \multicolumn{1}{|c|}{ Debit } & $\begin{array}{c}\text { Luas } \\
\text { Permukaan } \\
\text { genangan } \\
\text { Total }\end{array}$ \\
\hline & $\mathrm{m}^{2}$ \\
\hline Q 2 thn (30 Maret) & $11,093.46$ \\
\hline Q 5 thn & $21,491.70$ \\
\hline Q 10 thn & $23,642.84$ \\
\hline Q 25 thn (Ektrem) & $25,011.12$ \\
\hline Q 50 thn & $26,126.78$ \\
\hline Q 100 thn & $27,561.56$ \\
\hline
\end{tabular}

Sumber: hasil perhitungan

Tinggi rata-rata genangan akibat luapan Sungai Martapura di dalam kawasan SWPG Sudi Mampir sesuai hasil program HEC-RAS disajikan pada Tabel 10.
Tabel 10.Tinggi Genangan dalam Kawasan SWPG Sudi Mampir

\begin{tabular}{|l|r|}
\hline \multicolumn{1}{|c|}{ Debit } & $\begin{array}{c}\text { Tinggi Rerata } \\
\text { Genangan di } \\
\text { lahan }\end{array}$ \\
\hline & $\mathrm{m}$ \\
\hline Q 2 thn (30 Maret) & 0.20 \\
\hline Q 5 thn & 0.35 \\
\hline Q 10 thn & 0.40 \\
\hline Q 25 thn (Ektrem) & 0.50 \\
\hline Q 50 thn & 0.55 \\
\hline Q 100 thn & 0.65 \\
\hline
\end{tabular}

Sumber: hasil perhitungan

Volume genangan rata-rata akibat luapan Sungai Martapura di dalam kawasan SWPG Sudi Mampir sesuai hasil program HEC-RAS disajikan pada Tabel 11.

Tabel 11.Volume Genangan dalam Kawasan SWPG Sudi Mampir

\begin{tabular}{|l|r|}
\hline \multicolumn{1}{|c|}{ Debit } & \multicolumn{1}{c|}{$\begin{array}{c}\text { Volume } \\
\text { Genangan }\end{array}$} \\
\hline & $\mathrm{m}^{3}$ \\
\hline $\begin{array}{l}\text { Q 2 thn (08 Feb 30 } \\
\text { Maret) }\end{array}$ & $2,218.69$ \\
\hline Q 5 thn & $7,522.10$ \\
\hline Q 10 thn & $9,457.13$ \\
\hline Q 25 thn (Ektrem) & $12,505.56$ \\
\hline Q 50 thn & $14,369.73$ \\
\hline Q 100 thn & $17,915.01$ \\
\hline
\end{tabular}

\section{Alternatif Upaya Penanganan Dengan Sistem Polder}

Pembuatan sistem polder pada kawasan SWPG Sudi Mampir dilakukan penanggulan keliling pada kawasan tersebut. Tinggi tanggul dibuat dengan kala ulang 10 tahun debit banjir rancangan Sungai Martapura. Perencanaan drainase di dalam sistem polder pada kawasan SWPG Sudi Mampir digunakan kejadian aktual 30 maret 2016.

Sesuai dengan hasil analisis penanganan sistem drainase dalam polder kawasan SWPG Sudi Mampir dilayani dengan dua sistem kolam tampungan sementara, karena ketersediaan lahan yang sempit.

\section{Analisa Debit Inflow Kolam \\ Tampungan 1}

Kolam tampungan 1 direncanakan digunakan untuk melayani daerah pengaliran 
dengan luas mencapai $\pm 0,25 \mathrm{~km}^{2}$. Untuk mempermudah analisa, dibuat skema drainase pelayanan pada kolam tampungan 1 yang disajikan pada Gambar 9.

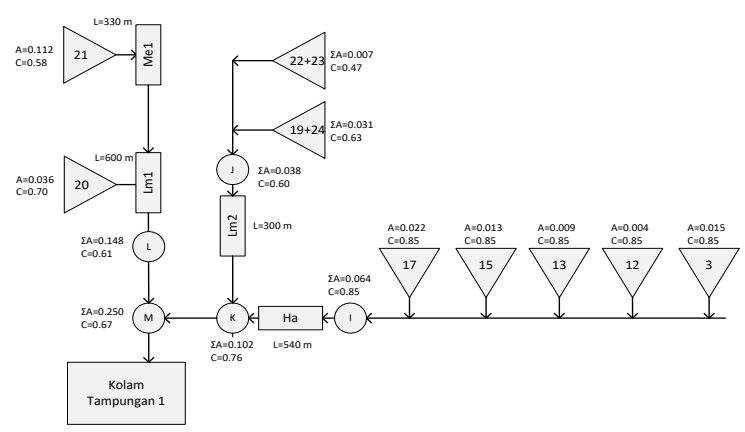

Gambar 9. Skema Sistem Drainase Kolam

Tampungan 1

Sumber: hasil analisa

Dari skema diatas didapatkan nilai $\mathrm{C}$ ekivalen gabungan untuk DPSal pada kolam tampungan 1 sebesar 0,67. Selanjutnya dilakukan trial dan error untuk menentukan kapasitas kolam tampungan dengan membuat hubungan antara komulatif outflow (kapasitas maksimum pompa yang akan digunakan) dan komulatif aliran inflow, sehingga didapatkan grafik hubungan antara komulatif inflow dan ourflow yang disajikan pada Gambar10.

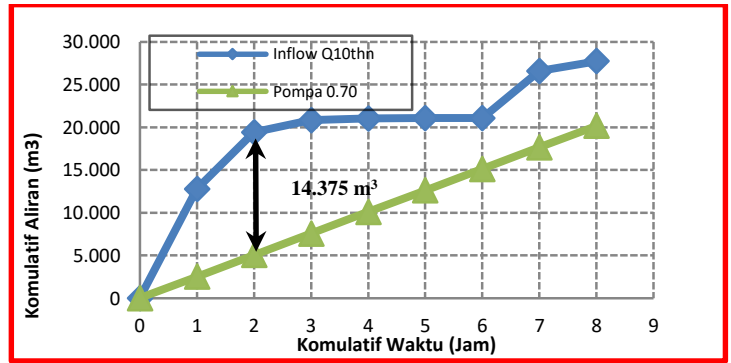

Gambar 10. Grafik Komulatif Aliran Inflow dan Outflow Kolam Tampungan 1 Sumber: hasil analisa

Dari grafik diatas didapatkan kapasitas kolam tampungan maksimum mencapai 14375 $\mathrm{m}^{3}$ dengan kapasitas pompa maksimum 0.7 $\mathrm{m}^{3} / \mathrm{dtk}$.

Data teknis kolam sebagai berikut:

\begin{tabular}{|c|c|}
\hline $\mathrm{P}_{1}$ & $=100 \mathrm{~m}$ \\
\hline $\mathrm{P}_{2}$ & $=70 \mathrm{~m}$ \\
\hline $\mathrm{P}_{3}$ & $=40 \mathrm{~m}$ \\
\hline $\mathrm{P}_{4}$ & $=53.33 \mathrm{~m}$ \\
\hline $\mathrm{h}$ & $=2.60 \mathrm{~m}$ \\
\hline Luas tampungan maks & $=5600 \mathrm{~m}^{2}$ \\
\hline Volume tampungan Maks & $=14560 \mathrm{~m}^{3}$ \\
\hline
\end{tabular}

$\begin{array}{ll}\text { Elevasi dasar kolam } & =+0.40 \mathrm{~m} \\ \text { Elevasi puncak kolam } & =+3.00 \mathrm{~m}\end{array}$

Dari hasil penelusuran banjir pada kapasitas kolam tampungan 1 dengan debit pemompaan maksimum sebesar $0.7 \mathrm{~m}^{3} / \mathrm{dtk}$ dapat menahan debit banjir di kolam tampungan 1 pada elevasi maksimum (HWL) +2.29 dengan selang waktu 3 jam. Setelah selang waktu 3 jam untuk lebih meng-efektif-kan volume kolam tampungan dan penghematan pada operasi pompa dilakukan penurunan kapasitas pompa. Dengan debit pemompaan maksimum sebesar $0.3 \mathrm{~m}^{3} / \mathrm{dtk}$ dapat menahan debit banjir di kolam tampungan 1 pada elevasi maksimum (HWL) + $2.98 \mathrm{~m}$ dengan selang waktu 5 jam.

\section{Analisa Debit Inflow Kolam Tampungan 2}

Kolam tampungan 2 direncanakan digunakan untuk melayani daerah pengaliran dengan luas mencapai $\pm 0,281 \mathrm{~km}^{2}$. Untuk mempermudah analisa, dibuat skema drainase pelayanan pada kolam tampungan 2 yang disajikan pada Gambar 11.

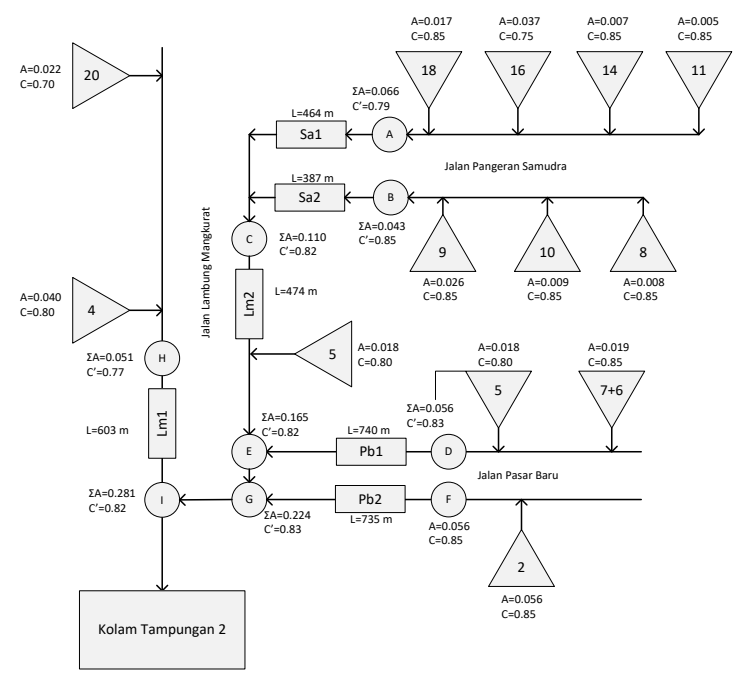

Gambar 11. Skema Sistem Drainase

Kolam Tampungan 2

Sumber: hasil analisa

Dari skema diatas didapatkan nilai $\mathrm{C}$ ekivalen gabungan untuk DPSal pada kolam tampungan 2 sebesar 0,82 . Selanjutnya dilakukan trial dan error untuk menentukan kapasitas kolam tampungan dengan membuat hubungan antara komulatif outflow (kapasitas maksimum pompa yang akan digunakan) dan komulatif aliran inflow, sehingga didapatkan 
grafik hubungan antara komulatif inflow dan ourflow yang disajikan pada Gambar 12.

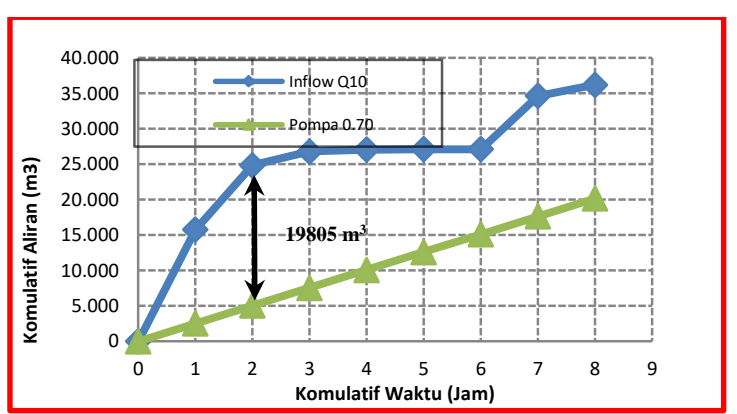

Gambar 12. Grafik Komulatif Aliran Inflow dan Outflow

Sumber: hasil analisa

Dari grafik diatas didapatkan kapasitas kolam tampungan maksimum mencapai 19805 $\mathrm{m}^{3}$ dengan kapasitas pompa maksimum 0.7 $\mathrm{m}^{3} / \mathrm{dtk}$.

Data teknis kolam tampungan 2

L1

L2

L3

$\mathrm{h}$

Luas tampungan

Volume tampungan Maks

Elevasi dasar

Elevasi puncak kolam

Berdasarkan penelusuran kapasitas kolam tampungan yang direncanakan dengan debit pemompaan maksimum, yaitu $0.7 \mathrm{~m}^{3} / \mathrm{dtk}$ dapat menahan debit banjir di kolam tampungan pada elevasi maksimum $(\mathrm{HWL})+2.46$ dengan selang waktu 1 jam.

\section{KESIMPULAN}

Kapasitas saluran drainase eksisting di SWPG Sudi Mampir sebagian besar tidak mampu menampung debit banjir yang terjadi 30 Maret 2016.

Genangan akibat luapan Sungai Martapura: Debit banjir yang terjadi di Sungai Martapura setara dengan kala ulang 2 tahunan, yaitu $566.54 \mathrm{~m}^{3} / \mathrm{dtk}$. Luas genangan akibat luapan sungai total pada SWPG Sudi Mampir sebesar 11.093,46 $\mathrm{m}^{2}$ dari luas total genangan sebesar 372.944,46 $\mathrm{m}^{2}$. Volume genangan akibat luapan sungai pada SWPG Sudi Mampir adalah sebesar 2.218,68 $\mathrm{m}^{3}$ dari volume total genangan sebesar $61.806 .30 \mathrm{~m}^{3}$. Tinggi rerata luapan sungai pada SWPG Sudi Mampir di sekitar lingkungan sungai adalah sebesar $20 \mathrm{~cm}$.

Genangan akibat limpasan hujan: Kenaikan muka air pasang Sungai Martapura yang waktunya bersamaan dengan datangnya hujan mempengaruhi sebaran genangan yang terjadi. Munculnya genangan disebabkan oleh meluapnya sungai dan terjadinya pembendungan aliran air dari saluran drainase akibat kenaikan pasang. Volume genangan akibat limpasan hujan 30 Maret 2016 pada SWPG Sudi Mampir sebesar 54.470,07 $\mathrm{m}^{3}$. Tinggi rata-rata genangan hujan di jalanan pada SWPG Sudi Mampir sebesar $47.1 \mathrm{~cm}$. Sedangkan tinggi rata-rata genangan hujan di lahan pada SWPG Sudi Mampir sebesar 10.3 $\mathrm{cm}$.

Berdasarkan hasil analisa, maka rekomendasi penanganan yang diusulkan adalah sebagai berikut: Normalisasi saluran drainase, pembuatan tanggul pada ruas sungai yang meluap, dan pembuatan sistem polder dengan pelayanan kolam tampungan pada kawasan SWPG Sudi Mampir.

\section{DAFTAR PUSTAKA}

Bappeda Provinsi Kalimantan Selatan. 1999. Program Pembangunan Prasarana Kota Terpadu (PPPKT) Kalimantan. Banjarmasin.

Kimpraswil. 2002. Review Outline Plan Drainase Se Kota Banjarmasin. Banjarmasin.

DSDAD Kota Banjarmasin. 2013. Studi Genangan Kota Banjarmasin.

Hendrasari, E. 2015. Kajian Penanganan Genangan Pada Sub Sistem Drainase Jangkok Kota Mataram. Tesis. Tidak dipublikasikan. Malang: Universitas Brawijaya.

Limantara, L. M. 2010. Hidrologi Praktis. Bandung: Lubuk Agung

Muhlis, A. 2012. Kajian Potensi Zona Genangan Air Kota Banjarmasin. Jurnal Penelitian. Banjarmasin: Politeknik Negeri Banjarmasin Jurusan Teknik Sipil.

Nugroho, V. T. K. 2012. Evaluasi Sistem Polder Kota Lama dan Bandarharjo Semarang Terhadap Pengendalian Banjir Dan Rob. Tesis. Tidak Dipublikasikan. Surakarta: Universitas Sebelas Maret.

Soemarto, C. D. 1987. Hidrologi Teknik. Surabaya: Usaha Nasional.

Suhardjono. 2015. Buku Ajar Drainase Perkotaan. Jurusan Teknik Pengairan. Malang: Universitas Brawijaya. 
Suripin. 2004. Sistem Drainase Perkotaan Yang Berkelanjutan. Yogyakarta: Andi Offset

Susilowati, 2006. Analisis Perubahan Tata

Guna Lahan dan Koefisien Limpasan
Terhadap Debit Drainase Perkotaan. Surakarta: Jurusan Teknik Sipil UNS. www.jawapos.com/read/2016/03/30/22475/huja n-deras-sejumlah-ruas-jalan-terendambanjir. 